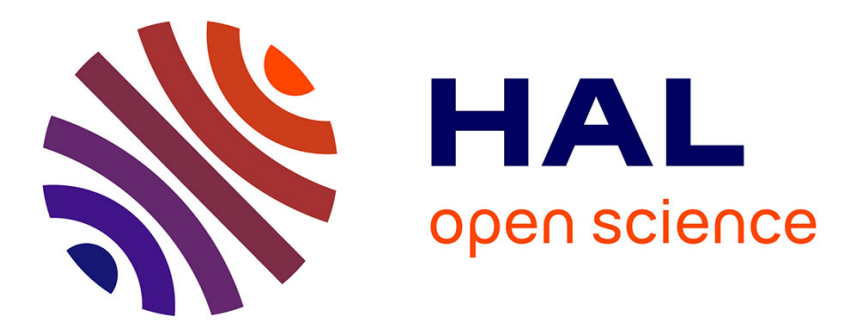

\title{
NO synthase isoforms specifically modify peroxynitrite reactivity
}

Amandine Maréchal, Tony A Mattioli, Dennis J Stuehr, J. Santolini

\section{To cite this version:}

Amandine Maréchal, Tony A Mattioli, Dennis J Stuehr, J. Santolini. NO synthase isoforms specifically modify peroxynitrite reactivity. FEBS Journal, 2010, 277 (19), pp.3963-73. 10.1111/j.17424658.2010.07786.x . cea-01234290

\section{HAL Id: cea-01234290 https://hal-cea.archives-ouvertes.fr/cea-01234290}

Submitted on 26 Nov 2015

HAL is a multi-disciplinary open access archive for the deposit and dissemination of scientific research documents, whether they are published or not. The documents may come from teaching and research institutions in France or abroad, or from public or private research centers.
L'archive ouverte pluridisciplinaire HAL, est destinée au dépôt et à la diffusion de documents scientifiques de niveau recherche, publiés ou non, émanant des établissements d'enseignement et de recherche français ou étrangers, des laboratoires publics ou privés. 


\title{
NO synthase isoforms specifically modify peroxynitrite reactivity
}

\author{
Amandine Maréchal ${ }^{1}$, Tony A. Mattioli ${ }^{1}$, Dennis J. Stuehr ${ }^{2}$ and Jérôme Santolini ${ }^{1}$ \\ 1 Laboratoire Stress Oxydant et Détoxication, iBiTec-S, CEA Saclay, Gif-sur-Yvette Cedex, France \\ 2 Department of Pathobiology, Lerner Research Institute, Cleveland Clinic, Cleveland, OH, USA
}

\begin{abstract}
Keywords
detoxification; NO synthase; oxidative stress; peroxynitrite; reactive nitrogen species
\end{abstract}

\section{Correspondence}

J. Santolini, Laboratoire Stress Oxydant et Détoxication, iBiTec-S and CNRS URA 2096, CEA Saclay, 91191 Gif-sur-Yvette Cedex, France

Fax: +33169088717

Tel: +33169085363

E-mail: jerome.santolini@cea.fr

(Received 12 May 2010, revised 8 July 2010, accepted 22 July 2010)

doi:10.1111/j.1742-4658.2010.07786.x
Nitric oxide synthases (NOSs) are multi-domain hemothiolate proteins that are the sole source of nitric oxide (NO) in mammals. NOSs can also be a source or a sink for peroxynitrite (PN), an oxidant that is suspected to be involved in numerous physiopathological processes. In a previous study, we showed that the oxygenase domain of the inducible NOS (iNOSoxy) reacts with $\mathrm{PN}$ and changes its oxidative reactivity [Maréchal A, Mattioli TA, Stuehr DJ \& Santolini J (2007) J Biol Chem 282, 14101-14112]. Here we report a similar analysis on two other NOS isoforms, neuronal NOS (nNOS) and a bacterial NOS-like protein (bsNOS). All NOSs accelerated $\mathrm{PN}$ decomposition, with accumulation of a similar heme intermediate. The kinetics of PN decomposition and heme transitions were comparable among NOSs. However, their effects on PN reactivity differ greatly. All isoforms suppressed PN two-electron oxidative activity, but iNOSoxy enhanced PN one-electron oxidation and nitration potencies, the oxygenase domain of nNOS (nNOSoxy) affected them minimally, and bsNOS abolished all PN reactivities. This led to the loss of both NOS and PN decomposition activities for nNOSoxy and iNOSoxy, which may be linked to the reported alterations in their electronic absorption spectra. Bacterial bsNOS was affected to a lesser extent by reaction with $\mathrm{PN}$. We propose that these differences in PN reactivity among NOSs might arise from subtle differences in their heme pockets, and could reflect the physiological specificity of each NOS isoform, ranging from oxidative stress amplification (iNOS) to detoxification (bsNOS).

\section{Introduction}

Nitric oxide synthases (NOSs) play an atypical role among the vast family of hemoproteins. Like cytochromes P450 and other hemothiolate proteins, their heme moiety performs highly selective and effective oxidation of substrates via the activation of dioxygen. However, the catalytic properties of NOSs are such that they lead to the biosynthesis of nitric oxide (NO) [1-3].
NOSs are homodimers comprising two distinct domains with specific catalytic roles. The reductase domain [4] is a flavoprotein with a ferredoxin-NADPreductase motif that shuttles electrons $[5,6]$ from NADPH via two co-factors (flavin adenine dinucleotide and flavin mononucleotide) to the oxygenase domain where the catalytic reaction takes place. The catalytic site comprises a heme B that is linked to the

\footnotetext{
Abbreviations

Arg, L-arginine; bsNOS, NOS-like protein isolated from Bacillus subtilis; Cpll, compound II of the chloroperoxidase and catalase catalytic cycle; DHR, dihydrorhodamine; DTPA, diethylenetriaminepentaacetic acid; eNOS, endothelial nitric oxide synthase; $\mathrm{H}_{4} \mathrm{~B}$, tetrahydrobiopterin, (6R)-5,6,7,8-tetrahydro-L-biopterin; HPA, 4-hydroxyphenylacetic acid; $\mathrm{HPA}^{-N_{2}}$, 3-nitroHPA; di-HPA, HPA dimer; iNOS, inducible nitric oxide synthase; nNOS, neuronal nitric oxide synthase; NO, nitric oxide; NOS, nitric oxide synthase; NOSoxy, oxygenase domain of NOS;

$\mathrm{PN}$, peroxynitrite; RNS, reactive nitrogen species.
} 
protein backbone by a proximal cysteine ligand [7]. The NOS heme catalyzes the two-step oxidation of L-arginine (Arg) [8] using 6R-tetrahydrobiopterin $\left(\mathrm{H}_{4} \mathrm{~B}\right)$ as an additional electron donor [9]. The first step, presumably similar to the mono-oxygenation mechanism of cytochromes P450, converts Arg into $N^{\omega}$-hydroxy-L-arginine [10]. The second step, specific to NOSs, converts $N^{\omega}$-hydroxy-L-arginine into citrulline, with NO being formed as a by-product [11,12]. This subtly regulated mechanism [13] is shared by numerous NOS isoforms and by a number of known NOS-like proteins (e.g. bacterial NOS-like proteins [14]). Despite similar 3D structures and catalytic mechanisms [1,7,15-18], NOSs display different if not contrary physiological activities. Constitutive mammalian NOSs (endothelial and neuronal NOSs, eNOS and nNOS) are involved in cGMP signaling cascades, and are implicated in the regulation of vascular tone or in neuronal communication [19,20]. Inducible NOS (iNOS) is involved in cytotoxic activities, such as the non-specific immune response [21,22]. The roles of bacterial NOS-like proteins remain mostly unknown [23-26], but several pieces of evidence indicate that they do not share the same catalytic mechanism as mammalian NOSs [27,28].

The variety of biological roles among NOS isoforms may be the result of the rich chemistry of NO [29]. Indeed, generation of secondary products called reactive nitrogen species (RNS) has been suggested to explain the various physiological effects of NO. For instance, peroxynitrite $(\mathrm{PN})$, a powerful oxidative and nitrative agent, is commonly associated with the cytotoxic and pathological activities of NOSs [30-33]. PN is believed to form in cells via the stoichiometric reaction of $\mathrm{NO}$ and superoxide anion $\left(\mathrm{O}_{2}{ }^{\circ-}\right)[34,35]$. However, NOS may also produce PN directly, either through 'uncoupling' conditions, in which both $\mathrm{NO}$ and $\mathrm{O}_{2}{ }^{\circ-}$ are formed [36-38], or via oxidation of the transient $\mathrm{Fe}^{\mathrm{II}} \mathrm{NO}$ complex [39,40].

Once produced, PN may be activated by Lewis acids such as protons, metals or metalloproteins [41,42]. PN activation has been reported for several hemoproteins [43-45]. However, their effect on PN chemical reactivity varies from $\mathrm{PN}$ isomerisation and scavenging for globins [43] to increased nitration activity for hemothiolate proteins [46]. This apparent discrepancy remains unexplained despite several reports on the mechanism of PN activation [47,48].

In a previous study, we showed that the heme-containing oxygenase domain of inducible NO synthase (iNOSoxy) was able to activate PN, accelerating its decomposition rate and changing its chemical reactivity to promote one-electron oxidation and nitration
[49]. Here we report a similar analysis on two other NOS isoforms: the constitutive nNOS and a NOS-like protein from Bacillus subtilis (bsNOS). We analyzed their capacity to accelerate PN decomposition, the kinetics of NOS-induced PN activation, and the related heme transitions. We also investigated the effect of such activation on PN reactivity and NOS properties.

\section{Results}

\section{All NOS isoforms activate PN decomposition}

We studied the effects of the heme environment on PN decomposition kinetics by comparing three NOS isoforms (iNOSoxy, nNOSoxy and bsNOS) that exhibit different physico-chemical properties. NOS solutions were rapid-mixed with $\mathrm{PN}$ at room temperature, and PN decomposition was monitored by absorbance changes at $302 \mathrm{~nm}$ (see Experimental procedures). Figure $1 \mathrm{~A}$ shows the PN apparent decay rates $\left(k_{\text {obs }}\right)$ as a function of nNOSoxy and bsNOS concentrations. Data previously obtained for iNOSoxy [49] are superimposed for comparison. Both nNOSoxy and bsNOS accelerate PN decomposition, with second-order rate constants for PN activation $\left(k_{\text {act }}\right)$ of $23.5 \pm 2.0 \times 10^{4}$ and $13.3 \pm 1.5 \times 10^{4} \mathrm{M}^{-1} \cdot \mathrm{s}^{-1}$, respectively (Table 1 ). As expected, no significant changes in PN spontaneous decomposition rates ( $y$ intercept) were noted as all data were obtained at the same $\mathrm{pH}$ value.

\section{NOS isoforms share similar mechanism of PN decomposition}

Superimposed absorption spectra showed that the kinetics of PN decomposition correlate with nNOSoxy and bsNOS heme spectral changes (Fig. S1B-D), as reported for iNOSoxy [49]. This confirms the involvement of NOS heme in the mechanism of PN decomposition for all NOSs. Analysis of the kinetic phases of PN activation by nNOSoxy at pH 6.4 (Fig. S1A,B) and by bsNOS at pH 7.4 (Fig. S1C,D) led to observations similar to those reported for iNOSoxy [49]. A series of transitions takes place during an initial phase (within a few milliseconds) that precedes the transient accumulation of a similar reaction intermediate (Fig. S1B-D) for all NOSs. The UV-visible absorption spectrum of the intermediate (Fig. 1B) is characterized by a Soret band between 442 and $447 \mathrm{~nm}$ and the presence of Q- $\beta$ and $-\alpha$ absorption bands at approximately 550 and $590 \mathrm{~nm}$. In the case of bsNOS, the Soret band is slightly shifted to the red $(447 \mathrm{~nm})$, and is broader (full width at half maximum of $52 \mathrm{~nm}$ ) than 


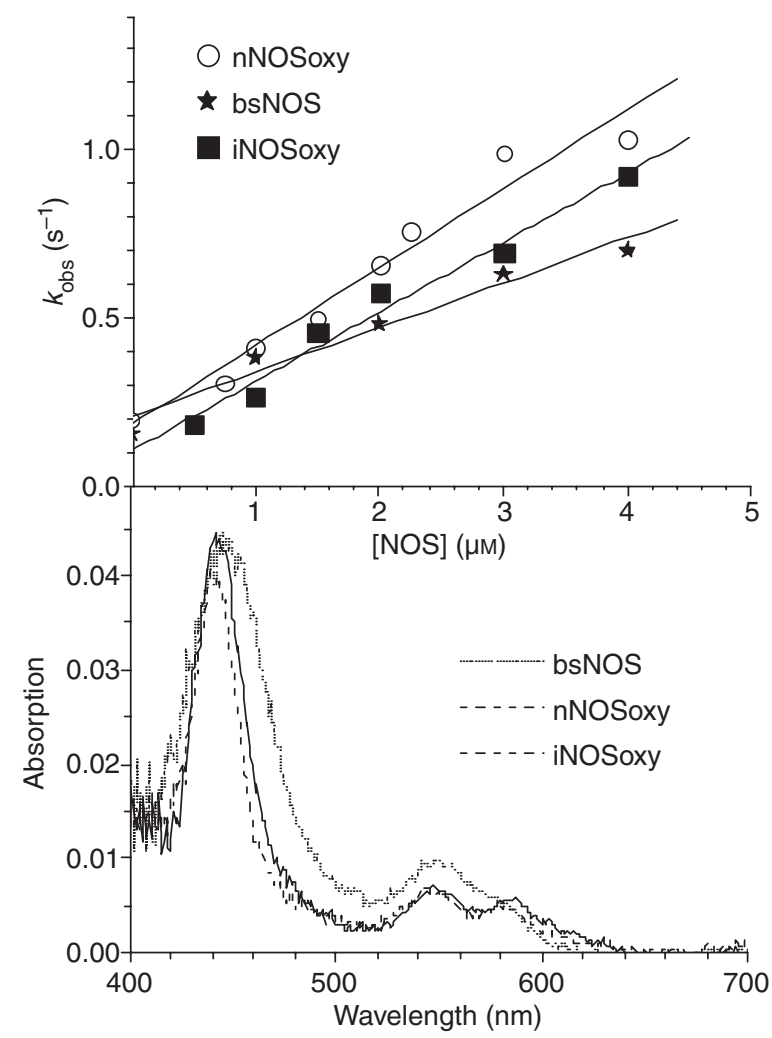

Fig. 1. Activation of peroxynitrite decomposition by the various NOSs. Top panel: $100 \mu \mathrm{M}$ PN were rapid-mixed with increasing concentrations of nNOSoxy or bsNOS at pH 7.4. Conditions were as described in Experimental procedures. Kinetics of the $302 \mathrm{~nm}$ absorption decay were fitted to mono-exponential functions. The apparent decay rate constants $\left(k_{\text {obs }}\right)$ are plotted as a function of the concentrations of nNOSoxy (open circles) and bsNOS (stars). Curves were fitted to a linear function to determine the rate constant for PN decomposition activation ( $k_{\text {act, }}$ slope) and PN spontaneous decomposition rate ( $k_{\mathrm{dec}}, y$ intercept). Values are reported in Table 1. Data for iNOSoxy are from [49]. Lower panel: extracted spectra of the intermediates observed on reaction of $100 \mu \mathrm{M}$ PN with $4 \mu \mathrm{M}$ bsNOS at $\mathrm{pH} 7.4$ (dotted line), nNOSoxy at $\mathrm{pH} 6.4$ (dashed line) and iNOSoxy at $\mathrm{pH} 6.4$ (solid line, data taken from [49]).

those observed for iNOSoxy and nNOSoxy (position $442 \mathrm{~nm}$; full widths at half maximum of 36 and $30 \mathrm{~nm}$, respectively). The accumulation and decay kinetics of this intermediate were fitted to a mono-exponential function for each isoform under the same concentration and $\mathrm{pH}$ conditions (data not shown). nNOSoxy and iNOSoxy intermediates showed similar formation and decay rates, and similar PN activation rates, whereas bsNOS exhibits two- to threefold slower formation and decay rates and a slower PN activation rate (Table 1). As observed for iNOSoxy [49], the last phase after PN consumption corresponds to the appearance of a modified ferric nNOSoxy species with
Table 1. Kinetic parameters for the reaction of PN with iNOSoxy, nNOSoxy and bsNOS. PN (100 $\mu \mathrm{m})$ was rapid-mixed with increasing concentrations of NOS isoforms in gas-free $0.1 \mathrm{M} \mathrm{KPi} \mathrm{pH} 7.4$ buffer. Time traces of PN decay at $302 \mathrm{~nm}$ were fitted to a monoexponential function. The observed rate of $\mathrm{PN}$ decomposition increases linearly with NOS concentration. The calculated slope represents the constant of activation of PN decomposition by NOS $\left(k_{\text {act }}\right)$. Heme spectral changes were analyzed upon reaction of $100 \mu \mathrm{M}$ PN with $4 \mu \mathrm{M}$ NOS. Characteristic intermediates were observed at $443 \mathrm{~nm}$ (nNOSoxy and iNOSoxy) and $447 \mathrm{~nm}$ (bsNOS). Time traces at 443 and $447 \mathrm{~nm}$ were fitted to mono-exponential functions to obtain $k_{\text {build }}$ (accumulation of intermediate) and $k_{\text {decay }}$ (decay of intermediate).

\begin{tabular}{llrr}
\hline & $k_{\text {act }}\left(10^{4} \mathrm{M}^{-1} \cdot \mathrm{s}^{-1}\right)$ & $k_{\text {build }}\left(\mathrm{s}^{-1}\right)$ & $k_{\text {decay }}\left(\mathrm{s}^{-1}\right)$ \\
\hline iNOSoxy & $21.0 \pm 2.0$ & $14.8 \pm 1.5$ & $1.22 \pm 0.04$ \\
nNOSoxy & $23.5 \pm 2.0$ & $16.1 \pm 4.1$ & $1.02 \pm 0.05$ \\
bsNOS & $13.3 \pm 1.5$ & $6.0 \pm 0.1$ & $0.40 \pm 0.01$ \\
\hline
\end{tabular}

absorption bands at 413 and $624 \mathrm{~nm}$, distinct from native nNOSoxy, which is characterized by a Soret absorption band at approximately $417 \mathrm{~nm}$ and a $\mathrm{Fe} \rightarrow \mathrm{S}$ charge transfer band at $650 \mathrm{~nm}$ (Fig. S1A,B). The bsNOS final spectrum is unaltered, with a Soret band at $404 \mathrm{~nm}$ and no absorbance change at approximately $624 \mathrm{~nm}$ (Fig. S1C,D). These results show that all NOSs bind PN at the heme and accelerate PN decomposition, with transient accumulation of a similar reaction intermediate. However, bsNOS does not show the same spectral modifications as mammalian NOSs upon PN activation.

\section{NOS isoforms diversely modify PN oxidative properties}

We investigated the effect of nNOSoxy and bsNOS activation on PN reactivity. The method was identical to that one previously reported for iNOSoxy [49] (see Experimental procedures). The two-electron oxidation reactivity of PN was assessed by comparing the production of rhodamine from dihydrorhodamine (DHR) in the absence and presence of NOS (Fig. 2A,B). The one-electron oxidation reactivity of PN was assessed by comparing the production of 4-hydroxy-phenylacetic acid dimers (di-HPA) from 4-hydroxy-phenylacetic acid (HPA) under the same conditions (Fig. 2C,D). As PN is known to be able to nitrate HPA to give HPA- $\mathrm{NO}_{2}$, the same HPA probe was also used to characterize the nitrative power of $\mathrm{PN}$ in the absence and presence of NOS (Fig. 2E,F). All data were fitted to a linear function of PN concentration to quantify PN reactivity in the absence and presence of NOS isoforms. Figure 3 compares the effect of NOS isoforms on the oxidation 


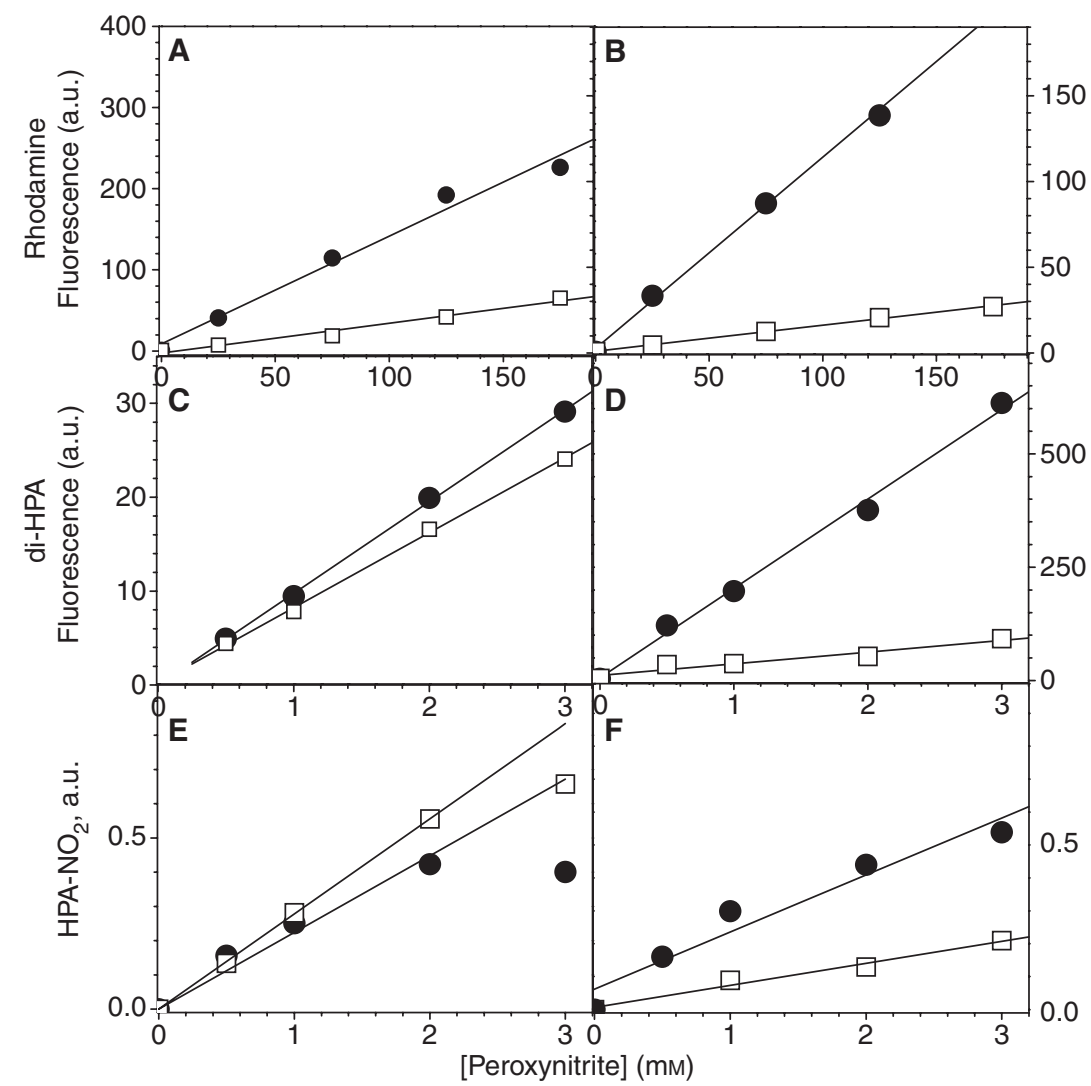

Fig. 2. Modification of peroxynitrite oxidative and nitrative properties by nNOSoxy and bsNOS. $(A, B)$ DHR two-electron oxidation as a function of PN concentration. Fluorescence spectra of rhodamine $\left(\lambda_{\text {excitation }} 500 \mathrm{~nm}\right.$ ) were recorded after reaction with various concentrations of peroxynitrite $(0,25,75,125$ and $175 \mu \mathrm{M})$. Fluorescence emission at $525 \mathrm{~nm}$ was plotted as a function of PN concentration in the absence of NOS (filled circles) or in the presence of $20 \mu \mathrm{m} n N O S o x y$ ( $A$, open squares) or bsNOS (B, open squares). (C,D) HPA dimerization as a function of PN concentration. Fluorescence spectra of di-HPA ( $\lambda_{\text {excitation }} 326 \mathrm{~nm}$ ) were recorded for various concentrations of peroxynitrite $(0,0.5,1,2$ and $3 \mathrm{~mm}$ ). Fluorescence emission at $405 \mathrm{~nm}$ was plotted as a function of PN concentration in the absence of NOSs (filled circles) or in the presence of $20 \mu \mathrm{M}$ nNOSoxy ( $C$, open squares) or bsNOS ( $D$, open squares). (E,F). Analysis by reverse-phase HPLC of $\mathrm{HPA}-\mathrm{NO}_{2}$ production upon reaction of HPA with peroxynitrite. Conditions are described in Experimental procedures. $\mathrm{HPA}_{\mathrm{N}} \mathrm{NO}_{2}$ production was plotted as a function of PN concentration in the absence of NOS (filled circles) or in the presence of $20 \mu \mathrm{M}$ nNOSoxy (E, open squares) and bsNOS (F, open squares). All curves were fitted to linear functions to compare the oxidative properties of free and NOS-activated peroxynitrite. a.u., arbitrary unit.

and nitration properties of PN. The bars indicate the percentage of reactivity when PN is activated by NOS compared to PN alone. Data obtained for iNOSoxy are included for comparison [49]. As previously reported, iNOSoxy quenches the PN two-electron oxidation capacity $(-56 \%)$ but increases its one-electron oxidation and nitration properties $(+40$ and $+90 \%$, respectively). Although nNOSoxy suppresses the PN two-electron oxidation ability $(-72 \%)$, it does not drastically modify its one-electron oxidation and nitration properties $(-18 \%$ and $+20 \%$, respectively). On the contrary, bsNOS appears to suppress all chemical reactivities of $\mathrm{PN}$ by $86 \%, 83 \%$ and $70 \%$, respectively (Fig. 3).

\section{Effect of NOS-induced PN activation on NOS activity}

We analyzed the effect of PN addition and NOSinduced activation on the NOS absorption spectrum. Ten to fifteen successive additions of four NOS equivalents of PN were mixed with NOS samples in the absence of substrate and co-factor (see Experimental procedures). UV-visible absorption spectra of the NOSs were recorded after each PN addition (Fig. 4). PN addition resulted in significant modification of the iNOSoxy absorption spectrum (Fig. 4C). A new absorption band appeared at $624 \mathrm{~nm}$, together with flattening of the $\alpha / \beta$ region, resulting in disappearance 


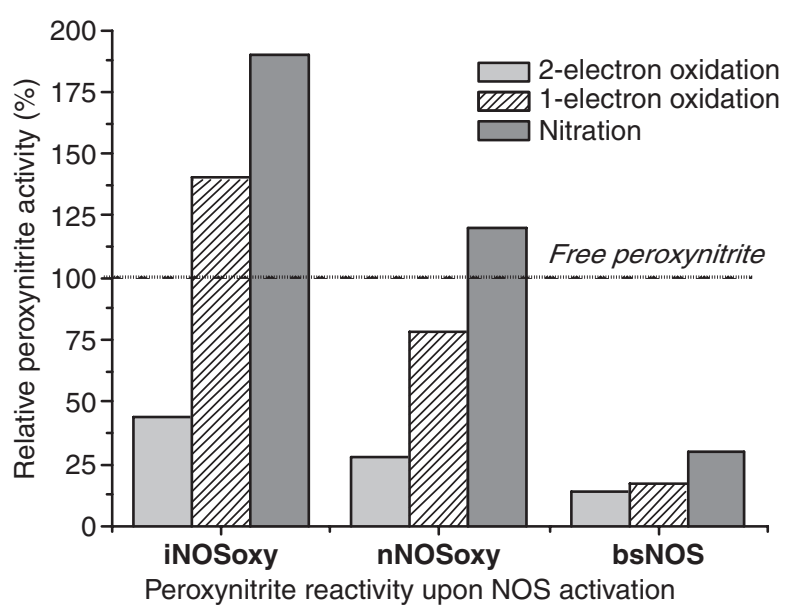

Fig. 3. Differential effects of NOS isoforms on PN-activated reactivity. Two-electron, one-electron and nitration properties of PN in the presence of bsNOS or nNOSoxy are derived from data in Fig. 4. Data for iNOSoxy are derived from [49]. PN reactivity in the presence of NOS was normalized to the control experiment performed in the absence of NOS (100\% reactivity of free peroxynitrite).

of the $543 \mathrm{~nm}$ band. In parallel, the Soret band shifts from 420 to $411 \mathrm{~nm}$ upon PN addition, as observed by Huhmer et al. [50]. Although the first transition is complete after five successive additions, the Soret shift is not yet complete after ten additions, suggesting that the transitions might correspond to distinct structural effects. The same experiments were repeated with nNOSoxy and bsNOS. The nNOSoxy spectral changes match those observed for iNOSoxy, although to a lesser extent: the Soret band is blue-shifted (413 nm after 15 additions), and a similar absorption bands appears at $620 \mathrm{~nm}$ (Fig. 4A). The pattern is notably different for bsNOS. We did not detect any significant increase in the absorbance at $624 \mathrm{~nm}$, and the Soret band is shifted from 401 to $408 \mathrm{~nm}$ (Fig. 4B). These results match the kinetic analysis of steady-state PN decomposition (above), which showed similar differences between bsNOS and mammalian NOSoxy final states.

Using the same samples, we analyzed the effects of PN activation on NOS catalytic properties. The protocols are similar to those used previously for iNOSoxy [49] (see Experimental procedures). We measured nitrite production by nNOSoxy (300 nM) and bsNOS $(1 \mu \mathrm{M})$ after each PN addition. NOS activity was normalized to NOS nitrite production in the absence of $\mathrm{PN}$ addition. Figure 5A shows that $\mathrm{PN}$ addition strongly inhibits nitrite production by nNOSoxy in a way similar to that previously reported for iNOSoxy (Fig. 5B, from [49]). No inhibition or decrease of the

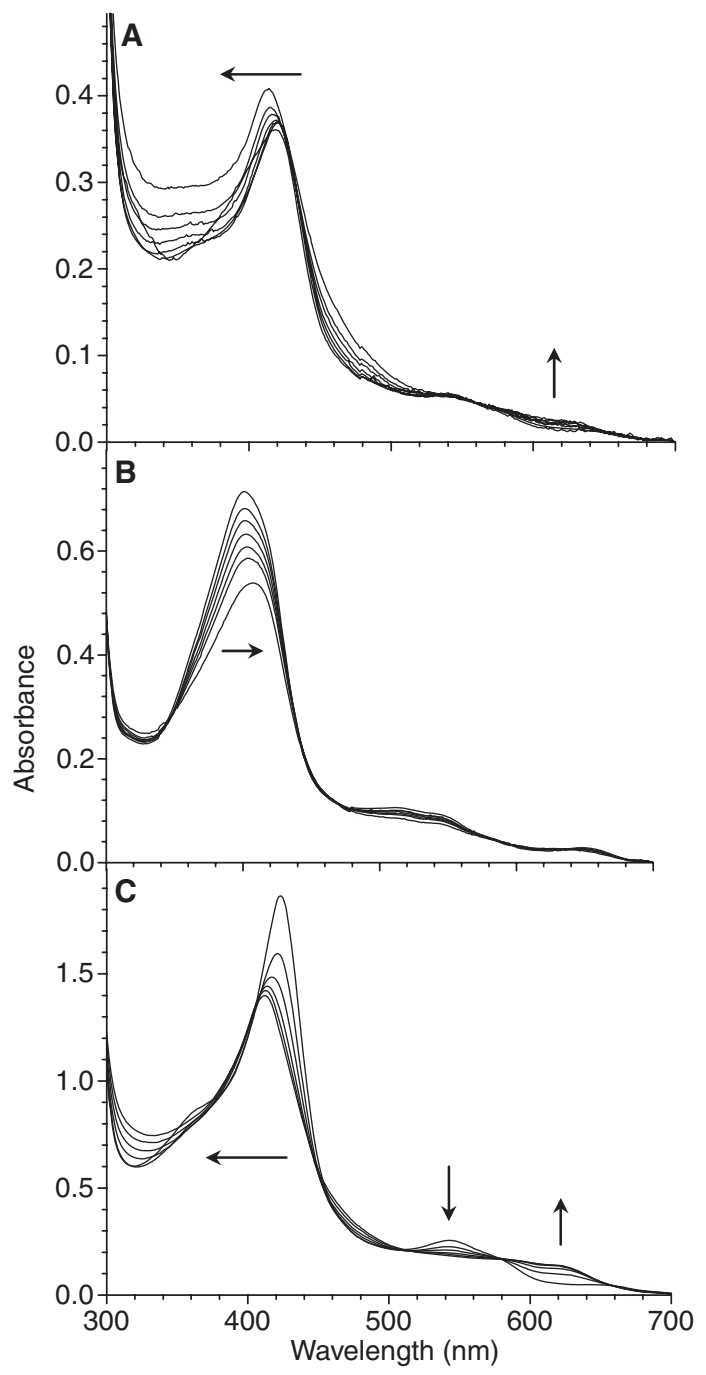

Fig. 4. Effect of activated peroxynitrite on NOS visible absorption spectrum. Superimposed UV-visible absorption spectra of the various NOSs after successive additions of PN. Successive additions (0-15) of four NOS equivalents of peroxynitrite were rapid-mixed with a $0.1 \mathrm{M} \mathrm{KPi} \mathrm{pH} 7.4$ solution containing nNOSoxy $(6 \mu \mathrm{M}, \mathrm{A})$ bsNOS $(10 \mu \mathrm{M}, \mathrm{B})$ or iNOSoxy $(24 \mu \mathrm{M}, \mathrm{C})$. Horizontal arrows indicate the shift of the Soret band; vertical arrows indicate changes in the $\alpha / \beta$ band and the $S \rightarrow$ Fe charge transfer band.

NO synthase activity was observed for bsNOS for up to 10 additions. We also characterized the effects of PN addition on NOS-induced PN activation. The kinetics of PN decay were monitored at $302 \mathrm{~nm}$ and fitted to a mono-exponential function after each successive PN addition (see Experimental procedures). Apparent decay rates were plotted as a function of the number of PN additions (Fig. 5). After several PN additions, nNOSoxy and bsNOS lose their ability to activate PN decomposition, as observed for iNOSoxy [49]. 


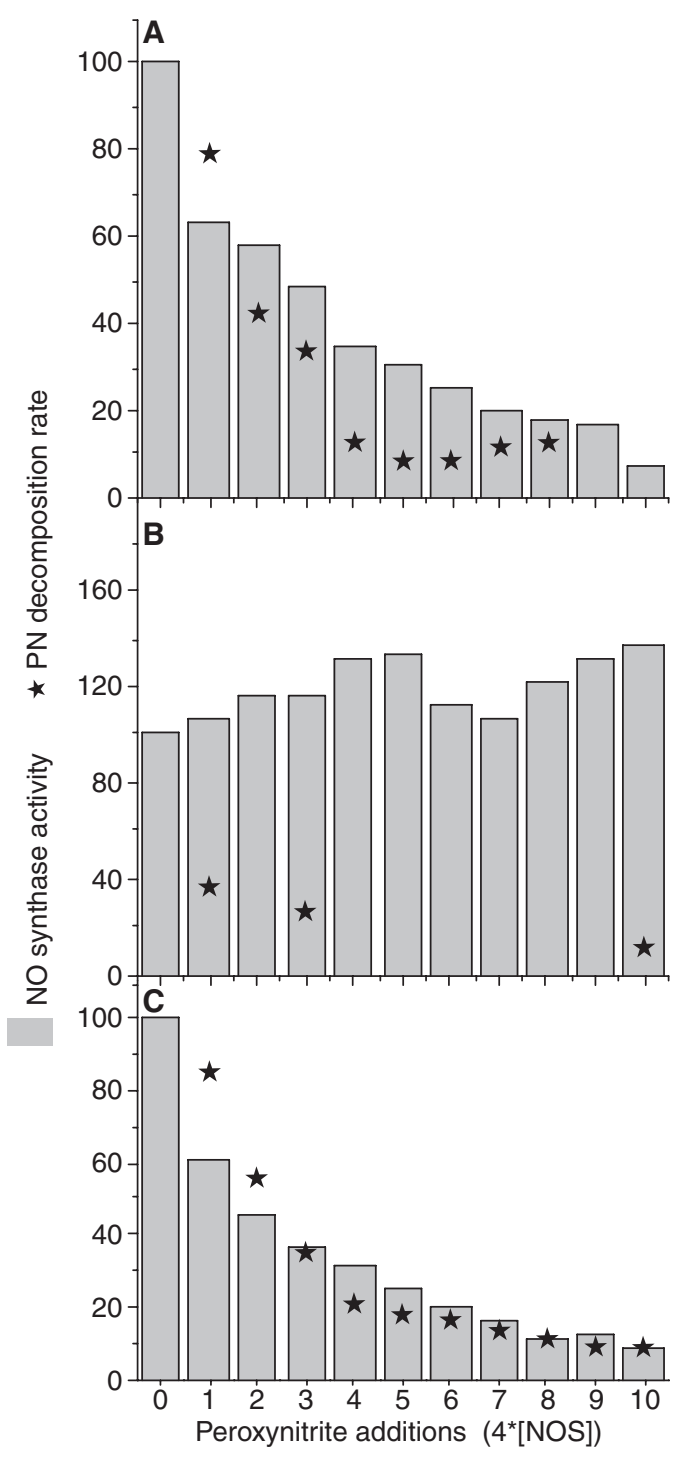

Fig. 5. Effects of activated peroxynitrite on NOS activities. (A) nNOSoxy NOS activity was measured after successive additions of PN (four NOS equivalents) using a standard Griess assay. Activities were normalized to control activity measured in the absence of PN, and are plotted as a function of the number of PN additions (histogram). The ability of nNOSoxy to activate PN decomposition was measured after each addition of peroxynitrite. PN decay kinetics were fitted to a mono-exponential function. Apparent rates of PN decomposition were plotted as a function of the number of PN additions (stars). (B) As (A) but for bsNOS. (C) as (A) for iNOSoxy; values are from [49].

\section{Discussion}

\section{Fate and nature of the catalytic intermediate}

All hemothiolate proteins (and proteins with a strong electron-donating proximal ligand) appear to catalyze the 'activation' of PN, i.e. the homolytic cleavage of the $\mathrm{PN} \mathrm{O}-\mathrm{O}$ bond, to lead to the concomitant formation of a compound II (CPII) and a $\mathrm{NO}_{2}{ }^{\circ}$ radical [44]. This system has been suggested to account for the increased one-electron oxidation and nitration activities of PN, and we previously suggested that the $443 \mathrm{~nm}$ intermediate observed on reaction of PN with iNOSoxy was a CpII [49]. We report here that two other NOSs (nNOSoxy and bsNOS) also rapidly react with $\mathrm{PN}$ to form a similar $443 \mathrm{~nm}$ intermediate, but show different and at times contrasting oxidation properties upon reaction with PN. Compared to iNOSoxy, nNOSoxy does not significantly affect PN oneelectron chemical reactivities, but bsNOS appears to suppress them. This is very intriguing, as the PN activation kinetics, the absorption spectrum of the reaction intermediate and its accumulation and decay rates are similar (Table 1 and Fig. S1), suggesting a common PN activation mechanism. There appears to be no correlation between accumulation of the $443 \mathrm{~nm}$ intermediate (common to all NOSs) and PN reactivity (different for each NOS). In fact, the differences observed in NOS/PN reactivity could occur downstream of CpII formation. Enhancement of the one-electron oxidation and nitration reactivities observed on $\mathrm{PN}$ activation by iNOSoxy could arise from a rapid escape of $\mathrm{NO}_{2}{ }^{\circ}$ from the heme pocket, as described for other hemoproteins $[44,48,51]$. In this context, the suppression of PN reactivity - as reported for bsNOS - could be explained by poor escape of $\mathrm{NO}_{2}{ }^{\circ}$. This is reminiscent of the slow NO off-rate observed for bsNOS $\left(k_{\text {off }}=0.23 \mathrm{~s}^{-1}\right.$, compared to $2.3 \mathrm{~s}^{-1}$ for iNOS), which has been attributed to the replacement of a valine residue by an isoleucine in the distal heme pocket of the bacterial homolog $[28,52,53]$. Thus, bsNOS is equally competent to produce the $\mathrm{CpII}-\mathrm{NO}_{2}{ }^{\circ}$ pair but would promote its recombination with subsequent release of nitrate. This suggests that the product of the reaction between PN and NOSs actually depends on subtle differences in the heme pockets, which are reflected in their spectroscopic fingerprints $[27,54,55]$.

Assignment of the $443 \mathrm{~nm}$ intermediate to a CpII for the reaction of NOS with PN is still awaiting experimental proof. It is supported by Newcomb et al., who observed, by X-ray absorption spectroscopy, the formation of a $\mathrm{CpII}$ intermediate on reaction of PN with native cytochrome P450 CYP119 [56], but this has been challenged by Behan et al., who suggested that the actual intermediate of the PN-P450 reaction could be a ferric-nitrosyl complex [57]. In addition, several reports have suggested that the reaction of PN activation might be too fast to permit characterisation of any reaction intermediates by conventional kinetic methods $[58,59]$. Consequently, the actual acti- 
vation of $\mathrm{PN}$ by NOSs, leading to formation of the CpII- $\mathrm{NO}_{2}{ }^{\circ}$ pair, might occur within the dead time of the reported kinetic analyses, and the $443 \mathrm{~nm}$ intermediate might result from side or end reactions forming other types of intermediates [51], such as the ferric-nitrosyl complex observed previously [57]. The series of successive transitions observed in the initial phase (first few milliseconds) might reflect several reactions occurring before accumulation of the $443 \mathrm{~nm}$ intermediate. Analysis of these extremely fast reactions, which is beyond the scope of this study, could allow identification of the very first reaction intermediates and characterisation of the molecular mechanism of $\mathrm{PN}$ activation.

\section{Implications on NOS physiological specificities}

This report highlights differences in heme-PN interactions between mammalian and bacterial NOSs. bsNOS appears to be the only hemothiolate protein that efficiently catalyzes the isomerisation of PN. The bsNOS active site appears to be specifically suited to rapid reaction with $\mathrm{PN}$ and its conversion into inert species, offering an effective means of PN detoxification. Moreover, unlike what has been observed for mammalian NOSs, the bsNOS structure is not dramatically altered by $\mathrm{PN}$ addition, and appears to be able to perform this detoxification task in the presence of a high concentration of PN. This protective role of bacterial NOS might also extend to other RNS and at first to NO [28,52]. Subtle differences in its heme pocket appear to allow bsNOS to trap and detoxify both $\mathrm{NO}$ and $\mathrm{PN}$. This unique ability suggests another rationale for the physiological activity of bacterial NOS-like proteins that could be involved in defense of bacteria against the host immune response.

On the other hand, the iNOSoxy active site appears to promote $\mathrm{PN}$ one-electron oxidative and nitrative power, coinciding with its cytotoxic role, which is probably linked to production of highly reactive RNSs. iNOSoxy appears to catalyze its self-nitration and inhibition in the presence of large excess of PN, whereas activation of stoichiometric amounts of PN leaves iNOSoxy unaltered and functional. This may provide a direct way to control the extent of RNS production and therefore regulate the intensity of the cellular oxidative stress.

Our report highlights the remarkable ability of the NOS proteins to selectively adjust PN reactivity towards oxidation/nitration or isomerisation, which might be directly linked to their biological roles.

\section{Experimental procedures}

All chemicals were purchased from Sigma-Aldrich (St Louis, MO, USA) except dihydrorhodamine (DHR) and rhodamine, which were purchased from Calbiochem (San Diego, CA, USA), and PN, which was purchased from Cayman Chemical (Ann Arbor, MI, USA). PN solutions between 37 and $45 \mathrm{~mm}$ in $0.3 \mathrm{M} \mathrm{NaOH}$ were stored as 50 and $100 \mu \mathrm{L}$ aliquots at $-80^{\circ} \mathrm{C}$. Before use, PN concentrations were measured by UV-visible spectroscopy $\left(\varepsilon=1670 \mathrm{M}^{-1} \cdot \mathrm{cm}^{-1}\right.$ at $302 \mathrm{~nm}$ ). Argon gas was purchased from Messer France SA (Asnières, France).

\section{Enzyme preparation}

Wild-type iNOS and nNOS oxygenase domains (iNOSoxy and nNOSoxy) containing a six-histidine tag at their C-terminus were expressed in Escherichia coli BL21 using the PCWori vector as described previously [60-62]. The bacterial NOS-like protein from Bacillus subtilis (bsNOS) was over-expressed in E. coli BL21 as previously reported [63]. All proteins were purified in the absence of Arg and $\mathrm{H}_{4} \mathrm{~B}$ using $\mathrm{Ni}^{2+}$-nitrilotriacetate affinity chromatography as described previously $[60,63]$. NOS concentrations were determined by the absorbance at $444 \mathrm{~nm}$ of the heme ferrous $0 \mathrm{CO}$ complex $\left(\mathrm{Fe}^{\mathrm{II}} \mathrm{CO} ; \varepsilon_{444}=74 \mathrm{~mm}^{-1} \cdot \mathrm{cm}^{-1}[64]\right)$.

\section{Stopped-flow experiments}

iNOSoxy, nNOSoxy and bsNOS were incubated in the absence of Arg and $\mathrm{H}_{4} \mathrm{~B}$ in a freshly anaerobized $100 \mathrm{mM}$ $\mathrm{KPi}, 300 \mu \mathrm{M}$ diethylenetriaminepentaacetic acid (DTPA) buffer at the desired $\mathrm{pH}$ value. PN solutions were prepared just before use by dilution of a fresh stock solution in anaerobized $0.01 \mathrm{~N} \mathrm{NaOH}$. Enzyme solutions were rapidmixed with the PN solution at $20{ }^{\circ} \mathrm{C}$. The mixing sequence was defined to give determined concentrations of PN and NOSs. $\mathrm{pH}$ values were checked after mixing, and only negligible variations were noticed. Rapid-sampling stoppedflow experiments were performed on a Bio-Logic SFM-300 instrument (Bio-Logic Science Instruments SA, Claix, France) fiber-optically coupled to a Tidas spectrograph (WPI Inc., Sarasota, FL, USA) equipped with a rapid-sampling 1024 diode array spectrometer ( $3 \mathrm{~ms}$ per spectrum). The light source was a $150 \mathrm{~W}$ Xe lamp. The spectral range of the monochromator was $200-1015 \mathrm{~nm}$, and the spectral resolution was $2 \mathrm{~nm}$ ( $0.8 \mathrm{~nm}$ per diode). The wavelength accuracy is quoted by the manufacturer as $0.1 \mathrm{~nm}$. Seven hundred and fifty UV-visible absorption spectra were recorded at various time intervals to encompass the whole kinetics (ranging between 2.3 and $40 \mathrm{~s}$ ). The apparatus dead time was estimated as $<2 \mathrm{~ms}$. The above protocol was adapted to the kinetic analysis of PN decay and related heme spectral transitions. 


\section{PN decay kinetics}

The PN decay kinetics were investigated for bsNOS and nNOSoxy using a protocol similar to that used for iNOSoxy [49]. PN decay was monitored by absorbance changes at $302 \mathrm{~nm}$ in the presence of increasing enzyme concentrations (from 0.5 to $4 \mu \mathrm{M}$ ). Three experiments were performed for each concentration. Time traces of the absorbance changes at $302 \mathrm{~nm}$ were multi-fitted to mono-exponential functions using ORIGIN 6.0 software (OriginLab Corporation, Northampton, MA, USA). This protocol was repeated three times. The derived apparent rate constants were averaged and plotted as a function of NOS concentration. The resulting data were fitted to a linear function to generate second-order rate constants.

\section{Kinetic analysis of heme spectral transitions}

PN $(100 \mu \mathrm{M})$ was rapid-mixed with $4 \mu \mathrm{M}$ NOS at three $\mathrm{pH}$ values $(6.4,7.4$ and 8.4). Time traces were monitored at wavelengths characteristic of specific species such as PN (302 nm), ferric enzyme (401-423 nm for the Soret band and $624 \mathrm{~nm}$ for the modified final state) and the major catalytic intermediate $(441-447 \mathrm{~nm})$. Time traces at $445 \mathrm{~nm}$ were used to determine the time $(t)$ of maximum accumulation of the intermediate, i.e. between 200 and $300 \mathrm{~ms}$ according to the experimental conditions. The UV-visible absorption spectrum of the intermediate was systematically calculated by subtracting an estimated fraction of the initial spectrum from the spectrum recorded at time $t$. This allowed us to estimate the Soret band for each NOS. Accumulation and decay rates of the intermediate were obtained from the mono-exponential fit of the time traces of absorption increase (from 0 to $250 \mathrm{~ms}$ ) and decrease (from $400 \mathrm{~ms}$ to the end of the kinetics) at this specific wavelength. Reported values correspond to the mean of three independent experiments.

\section{HPA fluorescence and HPLC assays}

The reaction of HPA with PN leads to formation of HPA dimers (di-HPA) and nitrated HPA $\left(\mathrm{HPA}-\mathrm{NO}_{2}\right)$, which can be isolated, identified and quantified by fluorescence spectroscopy and HPLC. The protocols used to analyze the effects of bsNOS and nNOSoxy on PN one-electron oxidation and nitration properties were identical to those previously described for iNOSoxy [49]. HPA (10 mM) was added to $100 \mu \mathrm{L}$ of a freshly degassed reaction buffer (0.1 M KPi, pH 7.4, $0.3 \mathrm{~mm} \mathrm{DTPA})$ in the absence or presence of $20 \mu \mathrm{M}$ NOS isoform. PN $(0.5,1,2$ or $4 \mathrm{~mm}$ final concentration) was added to the buffer, and the solution was immediately mixed vigorously. The solution was kept at room temperature for $10 \mathrm{~min}$ to ensure completion of the reaction, and was diluted to $1 \mathrm{~mL}$ for analysis. The production of di-HPA ( $\lambda_{\text {excitation }} 326 \mathrm{~nm}, \lambda_{\text {emission }}$
400/405 nm) was determined by fluorescence spectroscopy using Cary Eclipse fluorescence spectrometer (Varian Inc., Palo Alto, CA, USA). Emission intensity was plotted as a function of PN concentration. This series of experiments was repeated three times. Each plot was fitted to a linear function using ORIGIN 6.0 software (OriginLab Corporation), and the slopes of all curves were averaged. HPA$\mathrm{NO}_{2}$ production during the HPA reaction with $\mathrm{PN}$ was quantified by HPLC using the $365 \mathrm{~nm}$ absorption maximum. The areas of the HPA- $\mathrm{NO}_{2}$ chromatogram peak at $365 \mathrm{~nm}$ were plotted as a function of PN concentration, and the resulting curves were fitted to linear functions. Experiments were repeated twice.

\section{Dihydrorhodamine fluorescence assays}

Dihydrorhodamine (DHR) oxidation into fluorescent rhodamine was used to assess the two-electron oxidative properties of PN. The protocol used to analyze the effects of bsNOS and nNOSoxy on PN two-electron oxidative properties was identical to that previously described [49] for iNOSoxy. PN at increasing final concentrations of 0 , $10,20,30,40$ or $50 \mu \mathrm{M}$ was mixed vigorously with a degassed 0.1 M KPi pH 7.4, 0.3 mM DTPA buffer, containing $40 \mu \mathrm{M} \mathrm{DHR}$, in the presence or absence of the appropriate NOS isoform. Production of rhodamine was determined by fluorescence spectroscopy $\left(\lambda_{\text {excitation }} 500 \mathrm{~nm}\right.$, $\lambda_{\text {emission }} 525 \mathrm{~nm}$ ), and plotted as a function of PN concentration for each isoform. The curves were fitted to a linear function, and the slopes of three series of experiments were averaged.

\section{Analysis of the effects of PN addition on the UV-visible absorption spectra of NOS isoforms}

NOS isoforms in solution in $0.1 \mathrm{M} \mathrm{KPi} \mathrm{pH} 7.4$ buffer containing $0.3 \mathrm{~mm}$ DTPA were mixed with PN aliquots (four equivalents of NOS concentration in degassed $0.01 \mathrm{~N}$ $\mathrm{NaOH}$ ) in a quartz cuvette. The number of successive additions varied between 10 (iNOSoxy) and 15 (nNOSoxy and bsNOS). UV-visible absorption spectra were recorded $1 \mathrm{~min}$ after each addition. The same experiments were reproduced in the presence of $23.5 \mathrm{mg} \cdot \mathrm{L}^{-1}$ catalase to prevent any side reaction due to the presence/formation of hydrogen peroxide in solution.

\section{Analysis of the effects of PN addition on NOS activity}

The protocol used to analyze the effects of PN addition on bsNOS and nNOSoxy activities was identical to that previously described for iNOSoxy [49]. NOS samples (300 nM nNOSoxy and $1 \mu \mathrm{M}$ bsNOS) were rapid-mixed with up to ten successive additions of $\mathrm{PN}$ aliquots at four equivalents 
of NOS concentration. All samples were then washed by three successive cycles of concentration/dilution in a $0.1 \mathrm{M}$ KPi pH 7.4 buffer, using a Millipore (Billerica, MA, USA) membrane filter concentrator (30 kDa cut-off) to remove contaminants. Nitrite production of each protein sample was then measured using the Griess assay. Experiments were repeated three times. The kinetics of PN decomposition in the presence of $10 \mu \mathrm{M}$ NOS isoforms were recorded for the same protein samples using the protocol described above. Absorbance decays at $302 \mathrm{~nm}$ were fitted to a mono-exponential function.

\section{References}

1 Alderton WK, Cooper CE \& Knowles RG (2001) Nitric oxide synthases: structure, function and inhibition. Biochem J 357, 593-615.

2 Gorren AC \& Mayer B (2007) Nitric-oxide synthase: a cytochrome P450 family foster child. Biochim Biophys Acta 1770, 432-445.

3 Li H \& Poulos TL (2005) Structure-function studies on nitric oxide synthases. J Inorg Biochem 99, 293305.

4 Garcin ED, Bruns CM, Lloyd SJ, Hosfield DJ, Tiso M, Gachhui R, Stuehr DJ, Tainer JA \& Getzoff ED (2004) Structural basis for isozyme-specific regulation of electron transfer in nitric-oxide synthase. $J$ Biol Chem 279, 37918-37927.

5 Jáchymová M, Martásek P, Panda S, Roman LJ, Panda M, Shea TM, Ishimura Y, Kim JJ \& Masters BS (2005) Recruitment of governing elements for electron transfer in the nitric oxide synthase family. Proc Natl Acad Sci USA 102, 15833-15838.

6 Stuehr DJ, Tejero J \& Haque MM (2009) Structural and mechanistic aspects of flavoproteins: electron transfer through the nitric oxide synthase flavoprotein domain. FEBS J 276, 3959-3974.

7 Crane BR, Arvai AS, Ghosh DK, Wu C, Getzoff ED, Stuehr DJ \& Tainer JA (1998) Structure of nitric oxide synthase oxygenase dimer with pterin and substrate. Science 279, 2121-2126.

8 Stuehr DJ (1999) Mammalian nitric oxide synthases. Biochim Biophys Acta 1411, 217-230.

9 Stuehr DJ, Wei CC, Wang Z \& Hille R (2005) Exploring the redox reactions between heme and tetrahydrobiopterin in the nitric oxide synthases. Dalton Trans 21, 3427-3435.

10 Stuehr DJ, Kwon NS, Nathan CF, Griffith OW, Feldman PL \& Wiseman J (1991) $N^{\omega}$-hydroxy-L-arginine is an intermediate in the biosynthesis of nitric oxide from L-arginine. J Biol Chem 266, 6259-6263.

11 Mansuy D \& Boucher JL (2002) Oxidation of $N$-hydroxyguanidines by cytochromes $\mathrm{P} 450$ and NO-synthases and formation of nitric oxide. Drug Metab Rev 34, 593-606.
12 Wei CC, Wang ZQ, Hemann C, Hille R \& Stuehr DJ (2003) A tetrahydrobiopterin radical forms and then becomes reduced during $\mathrm{N}^{\omega}$-hydroxyarginine oxidation by nitric-oxide synthase. $J$ Biol Chem 278, 46668-46673.

13 Stuehr DJ, Santolini J, Wang ZQ, Wei CC \& Adak S (2004) Update on mechanism and catalytic regulation in the NO synthases. J Biol Chem 279, 36167-36170.

14 Crane BR, Sudhamsu J \& Patel BA (2010) Bacterial nitric oxide synthases. Annu Rev Biochem 79, 445-470.

15 Fischmann TO, Hruza A, Niu XD, Fossetta JD, Lunn CA, Dolphin E, Prongay AJ, Reichert P, Lundell DJ, Narula SK et al. (1999) Structural characterization of nitric oxide synthase isoforms reveals striking active-site conservation. Nat Struct Biol 6, 233-242.

16 Raman CS, Li H, Martasek P, Kral V, Masters BS \& Poulos TL (1998) Crystal structure of constitutive endothelial nitric oxide synthase: a paradigm for pterin function involving a novel metal center. Cell 95, 939-950.

17 Pant K, Bilwes AM, Adak S, Stuehr DJ \& Crane BR (2002) Structure of a nitric oxide synthase heme protein from Bacillus subtilis. Biochemistry 41, 11071-1109.

18 Bird LE, Ren J, Zhang J, Foxwell N, Hawkins AR, Charles IG \& Stammers DK (2002) Crystal structure of saNOS, a bacterial nitric oxide synthase oxygenase protein from Staphylococcus aureus. Structure 10, 16871696.

19 Sessa WC (2004) eNOS at a glance. J Cell Sci 117, 2427-2429.

20 Mungrue IN \& Bredt DS (2004) nNOS at a glance: implications for brain and brawn. J Cell Sci 117, 26272629.

21 Lowenstein CJ \& Padalko E (2004) iNOS (NOS2) at a glance. J Cell Sci 117, 2865-2867.

22 Bogdan C (2001) Nitric oxide and the immune response. Nat Immunol 2, 907-916.

23 Gusarov I \& Nudler E (2005) NO-mediated cytoprotection: instant adaptation to oxidative stress in bacteria. Proc Natl Acad Sci USA 102, 13855-13860.

24 Kers JA, Wach MJ, Krasnoff SB, Widom J, Cameron KD, Bukhalid RA, Gibson DM, Crane BR \& Loria R (2004) Nitration of a peptide phytotoxin by bacterial nitric oxide synthase. Nature 429, 79-82.

25 Patel BA, Moreau M, Widom J, Chen H, Yin L, Hua Y \& Crane BR (2009) Endogenous nitric oxide regulates the recovery of the radiation-resistant bacterium Deinococcus radiodurans from exposure to UV light. Proc Natl Acad Sci USA 106, 18183-18188.

26 Gusarov I, Shatalin K, Starodubtseva M \& Nudler E (2009) Endogenous nitric oxide protects bacteria against a wide spectrum of antibiotics. Science $\mathbf{3 2 5}$, 1380-1384.

27 Santolini J, Roman M, Stuehr DJ \& Mattioli TA (2006) Resonance Raman study of Bacillus subtilis NO synthase-like protein: similarities and differences with mammalian NO synthases. Biochemistry 45, 1480-1489. 
28 Wang ZQ, Wei CC \& Stuehr DJ (2010) How does a valine residue that modulates heme-NO binding kinetics in inducible NO synthase regulate enzyme catalysis? J Inorg Biochem 104, 349-356.

29 Lancaster JR Jr (2006) Nitroxidative, nitrosative, and nitrative stress: kinetic predictions of reactive nitrogen species chemistry under biological conditions. Chem Res Toxicol 19, 1160-1174.

30 Crow JP \& Beckman JS (1995) The role of peroxynitrite in nitric oxide-mediated toxicity. Curr Top Microbiol Immunol 196, 57-73.

31 Pacher P, Beckman JS \& Liaudet L (2007) Nitric oxide and peroxynitrite in health and disease. Physiol Rev 87, 315-424.

32 Radi R (1998) Peroxynitrite reactions and diffusion in biology. Chem Res Toxicol 11, 720-721.

33 Szabo C, Ischiropoulos H \& Radi R (2007) Peroxynitrite: biochemistry, pathophysiology and development of therapeutics. Nat Rev Drug Discov 6, 662-680.

34 Beckman JS \& Koppenol WH (1996) Nitric oxide, superoxide, and peroxynitrite: the good, the bad, and ugly. Am J Physiol 271, C1424-C1437.

35 Radi R, Peluffo G, Alvarez MN, Naviliat M \& Cayota A (2001) Unraveling peroxynitrite formation in biological systems. Free Radic Biol Med 30, 463-488.

36 Rosen GM, Tsai P \& Pou S (2002) Mechanism of freeradical generation by nitric oxide synthase. Chem Rev 102, 1191-1200.

37 Stuehr D, Pou S \& Rosen GM (2001) Oxygen reduction by nitric-oxide synthases. J Biol Chem 276, 14533-14536.

38 Vasquez-Vivar J, Kalyanaraman B \& Martasek P (2003) The role of tetrahydrobiopterin in superoxide generation from eNOS: enzymology and physiological implications. Free Radic Res 37, 121-127.

39 Santolini J, Meade AL \& Stuehr DJ (2001) Differences in three kinetic parameters underpin the unique catalytic profiles of nitric-oxide synthases I, II, and III. $J$ Biol Chem 276, 48887-48898.

40 Tejero J, Santolini J \& Stuehr DJ (2009) Fast ferrous heme-NO oxidation in nitric oxide synthases. FEBS $J$ 276, 4505-4514.

41 Crow JP (1999) Manganese and iron porphyrins catalyze peroxynitrite decomposition and simultaneously increase nitration and oxidant yield: implications for their use as peroxynitrite scavengers in vivo. Arch Biochem Biophys 371, 41-52.

42 Lymar SV \& Hurst JK (1998) Radical nature of peroxynitrite reactivity. Chem Res Toxicol 11, 714-715.

43 Herold S \& Fago A (2005) Reactions of peroxynitrite with globin proteins and their possible physiological role. Comp Biochem Physiol A Mol Integr Physiol 142, 124-129.

44 Daiber A \& Ullrich V (2002) Peroxynitrite reactions with heme and heme-thiolate (P450) proteins. Methods Enzymol 359, 379-389.
45 Floris R, Piersma SR, Yang G, Jones P \& Wever R (1993) Interaction of myeloperoxidase with peroxynitrite. A comparison with lactoperoxidase, horseradish peroxidase and catalase. Eur J Biochem 215, 767-775.

46 Daiber A, Schoneich C, Schmidt P, Jung C \& Ullrich V (2000) Autocatalytic nitration of $\mathrm{P} 450_{\mathrm{CAM}}$ by peroxynitrite. J Inorg Biochem 81, 213-220.

47 Herold S, Kalinga S, Matsui T \& Watanabe Y (2004) Mechanistic studies of the isomerization of peroxynitrite to nitrate catalyzed by distal histidine metmyoglobin mutants. J Am Chem Soc 126, 6945-6955.

48 Daiber A, Bachschmid M, Beckman JS, Munzel T \& Ullrich V (2004) The impact of metal catalysis on protein tyrosine nitration by peroxynitrite. Biochem Biophys Res Commun 317, 873-881.

49 Maréchal A, Mattioli TA, Stuehr DJ \& Santolini J (2007) Activation of peroxynitrite by inducible nitricoxide synthase: a direct source of nitrative stress. $J$ Biol Chem 282, 14101-14112.

50 Huhmer AF, Nishida CR, Ortiz de Montellano PR \& Schoneich C (1997) Inactivation of the inducible nitric oxide synthase by peroxynitrite. Chem Res Toxicol 10, 618-626.

$51 \mathrm{Su}$ J \& Groves JT (2009) Direct detection of the oxygen rebound intermediates, ferryl $\mathrm{Mb}$ and $\mathrm{NO}_{2}$, in the reaction of metmyoglobin with peroxynitrite. $J \mathrm{Am}$ Chem Soc 131, 12979-12988.

52 Wang ZQ, Wei CC, Sharma M, Pant K, Crane BR \& Stuehr DJ (2004) A conserved Val to Ile switch near the heme pocket of animal and bacterial nitric-oxide synthases helps determine their distinct catalytic profiles. J Biol Chem 279, 19018-19025.

53 Gautier C, Mikula I, Nioche P, Martasek P, Raman CS \& Slama-Schwok A (2006) Dynamics of NO rebinding to the heme domain of NO synthase-like proteins from bacterial pathogens. Nitric Oxide 15, 312-227.

54 Chartier FJ \& Couture M (2007) Interactions between substrates and the haem-bound nitric oxide of ferric and ferrous bacterial nitric oxide synthases. Biochem J 401, 235-245.

55 Rousseau DL, Li D, Couture M \& Yeh SR (2005) Ligand-protein interactions in nitric oxide synthase. J Inorg Biochem 99, 306-323.

56 Newcomb M, Halgrimson JA, Horner JH, Wasinger EC, Chen LX \& Sligar SG (2008) X-ray absorption spectroscopic characterization of a cytochrome P450 compound II derivative. Proc Natl Acad Sci USA 105, 8179-8184.

57 Behan RK, Hoffart LM, Stone KL, Krebs C \& Green MT (2007) Reaction of cytochrome $\mathrm{P} 50_{\mathrm{BM} 3}$ and peroxynitrite yields nitrosyl complex. J Am Chem Soc 129, 5855-5859.

58 Yukl ET, de Vries S \& Moenne-Loccoz P (2009) The millisecond intermediate in the reaction of nitric oxide with oxymyoglobin is an iron(III)-nitrato 
complex, not a peroxynitrite. J Am Chem Soc 131, 7234-7235.

59 Blomberg LM, Blomberg MR \& Siegbahn PE (2004) A theoretical study of myoglobin working as a nitric oxide scavenger. J Biol Inorg Chem 9, 923-935.

60 Ghosh DK, Crane BR, Ghosh S, Wolan D, Gachhui R, Crooks C, Presta A, Tainer JA, Getzoff ED \& Stuehr DJ (1999) Inducible nitric oxide synthase: role of the $\mathrm{N}$-terminal $\beta$-hairpin hook and pterin-binding segment in dimerization and tetrahydrobiopterin interaction. EMBO J 18, 6260-6270.

61 Abu-Soud HM, Gachhui R, Raushel FM \& Stuehr DJ (1997) The ferrous-dioxy complex of neuronal nitric oxide synthase. Divergent effects of 1-arginine and tetrahydrobiopterin on its stability. J Biol Chem 272, 17349-17353.

62 Gachhui R, Ghosh DK, Wu C, Parkinson J, Crane BR \& Stuehr DJ (1997) Mutagenesis of acidic residues in the oxygenase domain of inducible nitric-oxide synthase identifies a glutamate involved in arginine binding. Biochemistry 36, 5097-5103.

63 Adak S, Aulak KS \& Stuehr DJ (2002) Direct evidence for nitric oxide production by a nitric-oxide synthase- like protein from Bacillus subtilis. J Biol Chem 277, 16167-16171.

64 Stuehr DJ \& Ikeda-Saito M (1992) Spectral characterization of brain and macrophage nitric oxide synthases. Cytochrome P-450-like hemeproteins that contain a flavin semiquinone radical. J Biol Chem 267, 2054720550 .

\section{Supporting information}

The following supplementary material is available:

Fig. S1. Kinetic phases observed during PN activation by nNOSoxy and bsNOS.

This supplementary material can be found in the online version of this article.

Please note: As a service to our authors and readers, this journal provides supporting information supplied by the authors. Such materials are peer-reviewed and may be re-organized for online delivery, but are not copy-edited or typeset. Technical support issues arising from supporting information (other than missing files) should be addressed to the authors. 